\title{
Interferon Therapy
}

National Cancer Institute

\section{Source}

National Cancer Institute. Interferon Therapy. NCI Thesaurus. Code C15469.

The use of any form of interferon in the treatment of any disease or disorder. 